\title{
Invasion by human herpesvirus 6 and human herpesvirus 7 of the central nervous system in patients with neurological signs and symptoms
}

Tetsushi Yoshikawa, Masaru Ihira, Kyoko Suzuki, Sadao Suga, Tomoyo Matsubara, Susumu Furukawa, Yoshizo Asano

\begin{abstract}
Methods-A total of 43 children with neurological signs and symptoms were enrolled in the study. All children were suspected of having meningitis, and lumbar punctures were performed. Human herpesvirus 6 (HHV-6) and HHV-7 DNA was detected in cerebrospinal fluid (CSF) and peripheral blood mononuclear cells (PBMC) by nested polymerase chain reaction.

Results-Most patients had detectable serum antibody to both HHV6 and 7 . HHV6 DNA was detected in PBMC of 15 patients and in CSF cell pellet of seven. Corresponding figures for HHV7 were 28 and 6.2/7, and 5/6 with CSF viral DNA also had it in PBMC, respectively. No viral DNA was detected in CSF supernatants. The seven HHV6 CSF viruses were all variant $B$.
\end{abstract}

Conclusion-These data suggest that HHV-7 may invade the CNS.

(Arch Dis Child 2000;83:170-171)

Department of

Pediatrics, Fujita

Health University

School of Medicine,

Aichi, Japan

T Yoshikawa

M Ihira

K Suzuki

S Suga

Y Asano

Department of Pediatrics, Yamaguchi

University School of

Medicine, Yamaguchi,

Japan

T Matsubara

S Furukawa

Correspondence to:

Dr T Yoshikawa, Laboratory

of Virology, Research

Institute for Disease

Mechanism and Control,

Nagoya University School of

Medicine, Nagoya, Aichi,

4668550, Japan

email: tetsushi@

med.nagoya-u.ac.jp

Accepted 22 March 2000
Keywords: Herpesvirus; meningitis; CNS

It is now considered that both human herpesvirus 6 (HHV-6) and HHV-7 cause exanthem subitum. An association between exanthem subitum and seizures during the febrile stage of the disease, as well as less frequent postexanthematous residual encephalopathy, has been postulated. Since the identification of the causative agents for the disease, there have been several reports which suggest HHV-6 invades the central nervous system $(\mathrm{CNS})^{12}$ and causes CNS manifestations including febrile seizures. Recently, it has been reported that HHV-7 is also associated with the occurrence of febrile seizures and encephalitis/encephalopathy, and might invade the CNS. ${ }^{3-5}$ An epidemic of aseptic meningitis in the population around our university hospital occurred from May 1998 to the end of August 1998. In order to determine whether HHV-6 and HHV-7 invade into the CNS in these patients, we investigated the presence of both virus genomes in cerebrospinal fluid (CSF) obtained from patients with neurological signs and symptoms.

\section{Materials and methods}

PATIENTS

A total of 43 children ( 25 boys and 18 girls) seen in our university hospital with neurological signs and symptoms (for example, vomiting, irritability, headache, and stiff neck) and admitted to the hospital between 1 May 1998 and 31 August 1998 were eligible for enrolment. All patients were suspected of having meningitis, and lumbar punctures were performed at the discretion of the attending physician. Mean patient age was 6 years (ranging from 1 to 13 years). Informed consent was obtained from a guardian for all patients in this study. No patient's course was complicated by seizures. At the time of admission, EDTA peripheral blood and CSF were collected. No bacteria were isolated from any of the CSF specimens in this study. Patients who had CSF cell counts greater than $5 / \mu 1$ were diagnosed as having aseptic meningitis.

SAMPLE PREPARATION

CSF samples were collected from patients and separated into cell pellets and supernatant by slow centrifugation. Peripheral blood mononuclear cell (PBMC) fractions of each blood sample were isolated by density gradient centrifugation (Ficoll-Paque; Amersham Pharmacia Biotech, Uppsala, Sweden). All specimens were stored at $-70^{\circ} \mathrm{C}$ until the time of analysis.

\section{PCR AMPLIFICATION}

DNA was extracted from PBMCs, cell pellets in CSF, and $300 \mu \mathrm{l}$ of CSF supernatant by phenol-chloroform treatment followed by ethanol precipitation. Nested polymerase chain reaction (PCR) was carried out for amplification of HHV-6 DNA using two primer sets as described previously. ${ }^{2}$ The type of HHV-6 was determined by the presence of a HindIII site in each second PCR product, which was shown to be present in variant $B$, but not variant $A$ HHV-6.

ANTIBODY ASSAYS FOR HHV-6 AND HHV-7 Antibody titres to HHV-6 and HHV-7 were measured by an indirect immunofluorescence assay. 
Table 1 Clinical and laboratory findings in patients positive for $H H V-6$ or $H H V-7$ DNA in $C S F$

\begin{tabular}{|c|c|c|c|c|c|c|c|c|c|}
\hline \multirow{2}{*}{$\begin{array}{l}\text { No. of } \\
\text { cases }\end{array}$} & \multirow[b]{2}{*}{ Age (y) } & \multirow[b]{2}{*}{ Sex } & \multirow{2}{*}{$\begin{array}{l}\text { Cell counts } \\
\text { in CSF } \\
(\text { per } \mu l)\end{array}$} & \multicolumn{2}{|c|}{ Antibody titres* } & \multicolumn{2}{|c|}{$H H V-6 D N A$} & \multicolumn{2}{|c|}{$H H V-7 D N A$} \\
\hline & & & & $H H V-6$ & $H H V-7$ & $P B M C$ & $C S F$ & $P B M C$ & $C S F$ \\
\hline 1 & 7 & M & $<6$ & 8 & 16 & - & Yes & - & - \\
\hline 2 & 6 & $\mathrm{M}$ & $<6$ & $<4$ & 16 & - & Yes & - & - \\
\hline 3 & 5 & $\mathrm{~F}$ & 7 & 64 & 64 & - & Yes & Yes & - \\
\hline 4 & 8 & $\mathrm{~F}$ & 9 & ND & ND & - & Yes & Yes & - \\
\hline 5 & 7 & $M$ & 34 & 16 & 16 & Yes & Yes & Yes & - \\
\hline 6 & 8 & $\mathrm{~F}$ & 93 & 32 & 16 & - & Yes & - & - \\
\hline 7 & 6 & $\mathrm{M}$ & 45 & 64 & 8 & Yes & Yes & - & - \\
\hline 8 & 1 & $\mathrm{~F}$ & $<6$ & ND & ND & - & - & - & Yes \\
\hline 9 & 9 & $\mathrm{~F}$ & 7 & 16 & 16 & - & - & Yes & Yes \\
\hline 10 & 7 & $\mathrm{~F}$ & 7 & 32 & 64 & - & - & Yes & Yes \\
\hline 11 & 5 & $\mathrm{M}$ & 41 & 64 & 16 & - & - & Yes & Yes \\
\hline 12 & 5 & $M$ & 31 & 4 & 16 & Yes & - & Yes & Yes \\
\hline 13 & 8 & M & 16 & 8 & 16 & - & - & Yes & Yes \\
\hline
\end{tabular}

^Antibody titres were determined by indirect immunofluorescence assay. Plasma samples obtained at the time of admission were analysed.

ND, not done.

\section{Results}

Forty patients had HHV-6 (range $\times 4$ to $\times 64$ ) and 39 had HHV-7 (range $\times 4$ to $\times 64$ ) antibodies at the time of admission, indicating past infection with the viruses. HHV-6 DNA was detected in the PBMC of 15 and in the cell pellets of CSF of seven of 43 patients. All seven HHV-6 DNAs were digested with HindIII, indicating variant $\mathrm{B}$ (data not shown). In contrast to HHV-6, HHV-7 DNA was detected in the PBMC of 28 of 43 patients, and was detected in the cell pellets of CSF of six of 43 patients. Neither of the DNAs was detected in any CSF supernatant samples.

Table 1 shows the demographic characteristics of the patients from whom HHV-6 or HHV-7 genomes were detected in CSF, and the details of the results of PCR. Even though CSF cell counts were normal in cases 1,2 , and 8, HHV-6 or HHV-7 DNA was detected in CSF. Moreover, five of six patients with detection of HHV-7 DNA in CSF had the virus genome in PBMC. Only two of seven patients with detection of HHV-6 DNA in CSF had the virus genome in PBMC. As shown in table 1, all of the patients we examined had both HHV-6 and HHV-7 antibodies in acute plasma samples except for case 2 .

\section{Discussion}

The results of PCR analysis in this study showed not only the presence of HHV-6 DNA in the CNS but also the presence of HHV-7 DNA in the CNS in $14 \%$ of children with neurological symptoms. Two cases with primary HHV-7 infection complicated by seizures and acute hemiplegia have been reported previously, although in these cases HHV-7 DNA was not detected in CSF. ${ }^{3}$ Subsequently, it was shown that HHV-7 DNA could be detected in CSF obtained from a patient with CNS manifestations. ${ }^{4}$ Moreover, a recent prospective study found that primary HHV-7 infection was more likely to cause febrile seizures than primary HHV-6 infection. ${ }^{5}$ Taken together with the results of these reports, the present study suggests that $\mathrm{HHV}-7$ may invade and latently infect the CNS, or may be involved in CNS manifestations. However, the sample sizes are small and the subjects are restricted in this study. In order to confirm our findings, a prospective study including a larger number of cases is required.

HHV-7 DNA was detected in PBMC of all of the patients with positive CSF except for case 8. In contrast, only two of the seven patients from whom HHV-6 DNA was detected in CSF had viral DNA in PBMC. Moreover, all HHV-6 DNA detected in CSF was variant $\mathrm{B}$. It is possible that HHV-6 is more tropic to neurological tissues compared to HHV-7. Recently, Hall et al showed that HHV-6 variant A has greater neurotropism. ${ }^{6}$ The reason for this discrepancy may depend on differences in the epidemiology of the variants between the countries of these two studies.

Most of the patients in this study had both HHV-6 and HHV-7 serum antibodies, indicating that most patients had had past infection with both viruses. After primary infection, both viruses can latently infect several body sites including PBMC. Therefore, detection of the virus genomes in PBMC or cell pellets in CSF may reflect latent infection with the viruses. If we can detect virus DNA in cell free body fluids by PCR, then this suggests active virus infection. In the present study, however, we could not detect HHV-6 or HHV-7 DNA in CSF supernatant. This result could reflect two possible scenarios: either that both viruses can latently infect the CNS in such patients, or that there was virus DNA in the supernatant due to reactivation of the viruses, but at amounts below the detection limit. In order to resolve this issue, it will be necessary to improve the sensitivity of our PCR or to measure the viral RNA expression by reverse transcriptase PCR.

Sources of financial support: grants from Fujita Health Univertry of Education, Science and Culture, Japan.

1 Yoshikawa T, Nakashima T, Suga S, et al. Human herpesvirus-6 DNA in cerebrospinal fluid of a child with exanthem subitum and meningoencephalitis. Pediatrics 1992;89:888-90.

2 Suga S, Yoshikawa T, Asano Y, et al. Clinical and virological analyses of 21 infants with exanthem subitum (roseola infantum) and central nervous system complications. Ann Neurol 1993;33:597-603.

3 Torigoe S, Koide W, Yamada M, Miyashiro E, Taya KT, Yamanishi K. Human herpesvirus 7 infection associated with central nervous system manifestations. F Pediatr 1996;
129:301-5.

4 van der Berg JS, van Zeiji JH, Rotteveel JJ, Melchers WJ, Gabreels FJ, Galama JM. Neuroinvasion by human herpesvirus type 7 in a case of exanthem subitum with 9.

Caserta MT, Hall CB, Schnabel K, Long CE, D'Heron N. Primary human herpesvirus 7 infection: a comparison of human herpesvirus 7 and human herpesvirus 6 infection in children. F Pediatr 1998;133:386-9.

6 Hall CB, Caserta MT, Schnabel KC, et al. Persistence of human herpesvirus 6 according to site and variant: possible greater neurotropism of variant A. Clin Infect Dis 1988;26: 132-7. 